\title{
Hilfskasse für Schweizer Ärzte - seit über 125 Jahren
}

\begin{abstract}
Liebe Kolleginnen und Kollegen
Anfang Dezember wird unser Bettelbrief mit einem Separatum des Jahresberichtes 2008 und Einzahlungsscheinen verschickt. Damit die Hilfskasse auch nach ihrem 125. Geburtstag weiterhin in Not geratene Personen unterstützen kann, gelangt sie an alle volltätigen Kolleginnen und Kollegen mit der Bitte, mit einem Beitrag dieses so notwendige Sozialwerk der Schweizerischen Ärztegesellschaft zu unterstützen.
\end{abstract}

\section{Der Stiftungsrat muss immer wieder feststellen, dass} es trotz AHV, Lebensversicherungen und Renten noch Ärztinnen und Ärzte, Witwen und Angehörige gibt, die ohne die Beiträge der Hilfskasse in Not leben müssten

Die Hilfskasse für Schweizer Ärzte wurde im Jahre 1883 durch die Basler Ärzte Dr. A. Baader und Dr. A. Burckhard-Merian gegründet. Sie hat seither ihren Sitz in Basel beibehalten. Die Hilfskasse untersteht einem aus drei Ärzten und Ärztinnen gebildeten Stiftungsrat. Zurzeit sind es Dr. Urs Leibundgut (Präsident), Frau Dr. Susi Stöhr (Beisitzerin) und Dr. Urs Lüscher (Kassier). Das Stiftungsvermögen wird von der Bank La Roche \& Co verwaltet. Über alle Auszahlungen wird der Zentralvorstand der Schweizerischen Ärzteorganisation orientiert. Die Jahresabschlüsse werden durch ein unabhängiges Revisorat, vom Zentralvorstand und von der Stiftungsaufsichtsbehörde vom Justizdepartement BaselStadt geprüft.

Die Aufgabe der Hilfskasse ist die finanzielle Unterstützung von unverschuldet in Not geratenen Kolleginnen und Kollegen sowie deren Angehörigen.

\section{Ein Beispiel für die Unterstützung durch die Hilfskasse}

Ein 50-jähriger Arzt hat eine Muskelerkrankung, seit er 30-jährig ist. Er führt eine Praxis als Allgemeinarzt in der Ostschweiz. Er ist im Rollstuhl, praktiziert aber mit normalem Pensum weiter. Der Transfer vom Auto in den Rollstuhl ist schwierig. Er kann deswegen keine Hausbesuche machen.

Aufgrund der eingeschränkten Berufstätigkeit bezieht er eine Viertelrente bei der IV. Die Infrastrukgemischte Lebensversicherung mit Erwerbsausfallrente, die aber nur bezahlt, wenn er $100 \%$ arbeits-
Der Stiftungsrat muss immer wieder feststellen, dass es trotz AHV, Lebensversicherungen und Renten noch Ärztinnen und Ärzte, Witwen und Angehörige von Ärzten gibt, die ohne die Beiträge der Hilfskasse in schwerer Not leben müssten. Die Auszahlungen der Hilfskasse in den letzten zehn Jahren betrugen durchschnittlich ca. Fr. 318000.-. Etwa die Hälfte dieses Betrages konnte über lange Jahre hinweg aus den Zuwendungen der Ärzteschaft gedeckt werden, der Rest aus den Erträgen des zurzeit ca. Fr. 3,2 Millionen betragenden Vermögens.

Die Hilfskasse ist eine private Stiftung und erhält keine staatliche Unterstützung. Die drei Stiftungsräte führen ihre Tätigkeit ehrenamtlich aus.

Wie viele andere gemeinnützige Institutionen ist auch die Hilfskasse für Schweizer Ärzte nicht davor verschont geblieben, dass die jährlichen Zuwendungen aus der Ärzteschaft in den vergangenen Jahren zurückgegangen sind. Hinzu kamen Rückschläge an der Börse im Jahre 2002 sowie in jüngster Zeit, die die Erträge aus dem vorhandenen Kapital deutlich geschmälert haben. Aus diesen beiden Gründen musste in den letzten Jahren das Vermögen der Hilfskasse mehrfach leicht angegriffen werden.

Bitte schenken Sie unserem Bettelbrief, der Sie in den nächsten Tagen erreichen wird, Beachtung. Jede Spende zugunsten unverschuldet in Not geratener Kolleginnen und Kollegen ist willkommen.

Für den Stiftungsrat der Hilfskasse für Schweizer Ärzte Dr. Urs Leibundgut

PC-Konto der Hilfskasse für Schweizer Ärzte: 40-644-3 Basel

unfähig ist. Er liebt seinen Beruf und möchte weiterhin arbeiten. Er ist verheiratet und hat 3 Kinder. Die Familie bewohnt ein Einfamilienhaus mit einer hohen Hypothek. Mit den jetzigen Zinsen lebt er günstiger, als wenn er mit seiner 5-köpfigen Familie eine Mietwohnung bezahlen müsste.

In seiner Praxis generiert er Fr. 60000.- jährlich. Dadurch, dass seine Frau teilweise arbeitet, kann sich die Familie einigermassen über Wasser halten. Es bleiben jedoch dauernd Liquiditätsprobleme. Die Hilfskasse unterstützt die Familie mit Fr. 12000.- im Jahr. 